\title{
¿Cómo entenderse con Estados Unidos?
}

Hay mucho que aprender -y podemos evitar nuevas sorpresas- si, a propósito de la actitud asumida por EE. UU. en el conflicto del Atlántico Sur, se analiza la naturaleza profunda de las relaciones entre ese país y los de América Latina. Cada vez que se pasa revista a las mismas, se presentan posiciones contrapuestas. Quienes abogan por su consolidación o perfeccionamiento, hacen hincapié en los cambios -en sentido positivo- que han tenido lugar y que era necesario contemplar: desde hace medio siglo se reitera la palabra "nuevo" como antecedente inmediato o como expresión de lo que se deseaba. El "nuevo" trato de Franklin Roosevelt fue el antecedente de la política del "buen vecino", la "nueva frontera" de John Kennedy el de la "Alianza para el Progreso", etc. Por su parte, quienes desde América Latina criticaron cada uno de estos virajes, o los efectos reales que tuvieron, se dedicaron a mostrar lo que no había cambiado en esas relaciones.

Ha llegado el momento, sin duda, de asumir una posición más madura y razonable. Más allá de los juicios de valor que puedan merecer los hechos y circunstancias presentes, resultaría muy adecuado tomar explícitamente en cuenta lo que no ha cambiado ni, presumiblemente, cambiará en los próximos años, junto con lo que efectivamente se esté modificando. Con tal fin es necesario pasar rápida revista a la historia de esas relaciones, con énfasis particular en las últimas décadas.

Casi desde la independencia de los países latinoamericanos se definieron tres grandes campos de relación entre EE. UU. y América Latina: económico, ideológico y geopolftico. En los tres, la conjunción de una asimetría creciente y la defensa de intereses particulares dio lugar a tres constantes:

"Jorge A. Sábato es miembro de la Fundación Bariloche. Este artículo se basa en uno de los apartados del documento titulado "Cooperación para el desarrollo: algunas reflexiones y propuestas", que fue elaborado por Jorge A. Sábato, Dante Caputo y Jorge Federico Sábatơ, publicado en la revista "Estudios Internacionales", No 53, enero-marzo 1981, y escrito en mayo de 1980. 
a) En el campo económico, a la obtención de privilegios y ventajas, cambiantes pero siempre presentes: desde los primeros tratados de comercio en el siglo pasado hasta las actuales tentativas para garantizar el suministro y precios de materias primas esenciales; desde la protección a los primeros comerciantes y el cobro compulsivo de deudas empleando las fuerzas armadas estadounidenses, hasta la ayuda de agencias secretas para defender a empresas transnacionales como la ITr.

b) En el campo ideológico-cultural se puede observar una formidable presión para difundir las concepciones políticas y las pautas de vida de EE. UU. en todo el continente. Hasta 1930 esta influencia derivaba simplemente del liderazgo incontestado de EE. UU. como el país política y socialmente más "avanzado" del mundo. La revolución soviética y la emergencia del fascismo, unidas a la crisis económica mundial, quebraron ese liderazgo, transformando el campo ideológico en un ámbito explícito de controversia. Entonces se hizo clara la importancia de la influencia ideológica y la difusión de pautas culturales en la trabazón de intereses económicos y políticos, y EE. UU. lanzó una ofensiva colosal en todos los frentes, utilizando todos los medios culturales - directos e indirectosa su alcance.

c) En el campo geopolítico también se han dado ciertas constantes, tanto en la faz militar como en la estrictamente política. EE. UU. ha tratado de impedir en América Latina la formación de un poder militar capaz de competir, o siquiera desafiar en cualquier área sus propias fuerzas armadas. Desde la doctrina Monroe, dirigida a neutralizar la influencia británica y de otras potencias europeas durante el siglo pasado y a afirmar la propia, hasta la crisis de los cohetes en Cuba, y el Tratado de No Proliferación Nuclear, éste ha sido un rasgo sistemático en sus relaciones con América Latina. Las ventajas más ostensibles de tal posición se reflejaron en la expansión territorial ocurrida desde mediados del siglo xIx, a costa de México, hasta la instalación en el Garibe a fines de ese siglo. Otros ejemplos fueron las intervenciones directas o indirectas, realizadas tanto bajo gobiernos republicanos o demócratas, como lo atestiguan - una vez más- los casos más recientes: el golpe de Estado contra Arbenz, en Guatemala, bajo la administración de Eisenhower; Ia invasión de Bahía Cochinos, en Guba, bajo Kennedy; la invasión de Santo Domingo, bajo Johnson; la participación en el golpe de Estado con Allende, en Chile, bajo Nixon.

La recapitulación de estas constantes, tan conocidas y el reconocimiento de la debilidad de los países latinoamericanos en sus reIaciones con EE. UU., serían sin duda muy útiles, paradójicamente, para amenguar sus desventajas. La ocultación pudorosa, o cómplice, ha conducido, por el contrario, a que, en nombre de los princi- 
pios y las buenas maneras internacionales se los proclamara iguales de derecho con EE. UU. cuando eran desiguales de hecho y que, en nombre de los "intereses vitales" de EE. UU. se los tratara como desiguales de hecho, cuando debieran ser iguales de derecho.

Por eso mismo, para las naciones latinoamericanas sería beneficioso que en sus relaciones con EE. UU. se adoptaran criterios similares a los usados para tratar a las minorías en el interior de ese mismo país, reconociendo la desigualdad cuando es preciso asegurar una oportunidad equivalente en las transacciones y aceptando su igualdad cuando ejercen los derechos libres y soberanos de toda nación para decidir su propio destino.

Pero no cabe duda de que, por las mismas razones apuntadas antes, EE. UU. no aceptará un enfoque de esta naturaleza si no le es beneficioso. Pero sin descartar en forma absoluta que ello pueda llegar a serlo, esa no es razón para que los países latinoamericanos no lo adopten desde ya.

Lo que caracteriza una transacción entre iguales es la transparencia de los intereses que cada uno pone en juego. Cuando una de las partes puede conocer los intereses de la otra y ocultar los propios en el trato, crea una ventaja a su favor. Y cuando una de las partes, por otros motivos, tiene ventajas sobre la otra antes mismo de realizar la transacción, le es más fácil ocultar los intereses que pone en juego, aumentando de ese modo los privilegios. Eso es lo que muestra de manera terminante el análisis de las relaciones entre EE. UU. y América Latina, como Io ejemplifica con meridiana claridad la triste historia de la Alianza para el Progreso.

En la Carta de Punta del Este -que la definió- Ex. uv. endosó casi textualmente las propuestas reformistas latinoamericanas que la CEPAL había contribuido a elaborar, ordenar y difundir por todo el continente. Pero más allá de este acuerdo en las ideas, la negociación fue ardua en el campo más concreto de los intereses. EE. UU. prometió una ayuda económica pública masiva, junto a una activación importante de la cooperación; pero también se pidieron garantías para las inversiones privadas norteamericanas y se retacearon concesiones comerciales a las exportaciones latinoamericanas. Se sumaron además exigencias mucho más significativas $-\mathrm{y}$ que tendrían efectos profundos y perdurables- en el ámbito de la seguridad militar, lo que significó establecer (o más precisamente institucionalizar lo que ya existía desde 1960 con el nombre de Conferencia de los Ejércitos Americanos) una vinculación estrecha y directa en las fuerzas armadas de EE. Uu. y las de América Latina, vinculación presidida por la aceptación de una misión común de "combate a la infiltración y a la subversión comunista".

De hecho, aunque quizá no se percataron en ese momento, los gobiernos latinoamericanos aceptaban renunciar a su capacidad 
política de definir la doctrina $y$ de fijar los objetivos que debían guiar a sus propias fuerzas armadas.

Aun cuando el gobierno de EE. UU. y los movimientos reformistas de América Latina parecían haberse puesto de acuerdo, sus intereses concretos seguían siendo bien diferentes. Para los reformistas la transformación política, social y económica era lo esencial y la cuestión de la seguridad frente a los avances revolucionarios resultaba secundario, dependiente fundamentalmente del éxito de aquella transformación. Para EE. UU. Ia prioridad era exactamente al revés. $Y$ esta discrepancia era mucho más que semántica: definía el contenido que una y otra parte otorgaban al acuerdo $y$, cosa no menos importante, planteaban horizontes temporales distintos en la acción de uno y otro. Porque la transformación latinoamericana era un proceso que, para fructificar, exigfa una acción a largo plazo, en tanto que la cuestión de la seguridad tenía efectos inmediatos. Consiguientemente, la manera de proceder de una y otra parte se ajustaría a las prioridades que cada una se había fijado y las discrepancias aparecerían con rapidez. También emergerían a causa de ello nuevos actores en el escenario.

En un examen retrospectivo parece claro que la posición de EE. vu. resultó mucho más realista que la de los reformistas latinoamericanos. Porque en los veinte años transcurridos desde entonces quedó de manifiesto que desarrollo económico, progreso social y democratización política no estaban indisolublemente unidos ni eran los componentes básicos de un proceso inevitable, como se había postulado con todo optimismo. En las dos décadas pasadas se ha asistido a casi todas las otras combinaciones posibles, salvo justamente aquella que se consideraba más probable.

Lo ocurrido es desolador para quienes lideraron política o intelectualmente los movimientos reformistas y democráticos de América Latina hace veinte años. En contraste, los resultados obtenidos por EE. UU. fueron bastante satisfactorios. A diferencia de lo ocurrido en Asia y Africa en el mismo perfodo, la influencia preponderante de EE. UU. en América Latina se mantuvo sin mayores sobresaltos desde la revolución cubana a la fecha. Hasta la reciente revolución en Nicaragua, EE. UU. ha mantenido un control bastante rígido para prevenir la influencia de algún país comunista sobre un país latinoamericano. Al menor atisbo, la menor posibilidad de alterar el balance de influencia preexistente ha sido quebrada de raíz, aun cuando esa posibilidad pareciera muy indirecta. Es bastante discutible que tal control haya sido bueno para los latinoamericanos - más bien parecería lo contrario- e incluso para EE. UU., pero no ćaben dudas que benefició a grupos específicos y privilegiados de latinoamericanos en distintos países, o así como a ciertos intereses privados de empresas y compañías norteamerica- 
nas, además de la opinión favorable que ese control ha merecido de parte de sectores militares y políticos estadounidenses.

La experiencia de que ha habido beneficiarios netos, tanto en América Latina como en EE. UU, del conjunto de compromisos que constituyeron la Alianza para el Progreso, sirve para comprender un poco mejor lo ocurrido en estos últimos veinte años. Ante todo la experiencia sirvió para demostrar que se podía promover un desarrollo económico mucho más beneficioso para grupos sociales restringidos que para el conjunto de la población del país en que ocurría.

Pero al lado de este fenómeno cuyas características varían de nación en nación, otros hechos tuvieron un alcance más general, una infiuencia más profunda.

El primero es que la doctrina de la seguridad continental sirvio para que sectores sociales y económicos privilegiados internacionalizaran sus enfrentamientos internos con el resto mayoritario de la población. Las luchas contra la injusticia social, por una mejor distribución de la riqueza y por el cambio de las estructuras generadoras de atraso y de pobreza pudieron ser calificadas - iy lo fueron!- como productos de la subversión internacional comunista. Recíprocamente, la défensa del prituilegio se transmutó en defensa del modo de vida occidental y cristiano. La línea de lo legal y lo legitimo en la actividad política interna se corrió abruptamente hacia la derecha en muchos países. Ideas y concepciones que se podían exponer libre y públicamente hace quince, veinte, cuarenta y aún ochenta años, son hoy posibles de las penas legales más severas y de las sanciones encubiertas más atroces. Incluso resultan sospechosas, cuando no criminales, posiciones sostenidas hace medio siglo por miembros de gobiernos conservadores. La doctrina de la seguridad continental, contracara de la retórica reformista de la Alianza para el Progreso y de los solemnes compromisos contraídos en la Carta de Punta del Este, sirvió de punto de apoyo para dar origen a un conjunto de regímenes autoritarios y antidemocráticos.

La experiencia vivida muestra así que los intereses norteamericanos quedaron en la penumbra, cuando sería más útil para todos que constara en negro sobre blanco, explícitamente, la preocupación de EE. UU. por sus propios problemas y los beneficios que piensa obtener en compensación por lo que promete conceder a los latinoamericanos. Es una transacción en la que las dos partes ganan y pierden algo; lo importante es saber cuánto, porque la oscuridad deja siempre la sospecha de que se perdió más de lo que se ganó.

Por todo lo dicho, las relaciones entre EE. uU. y América Latina debieran basarse en Ios siguientes elementos principales:

a) Existen intereses propios, y a menudo contrapuestos, entre las partes. En particular, EE. UU. tiene intereses planetarios, cosa 
que no ocurre con América Latina. Además, no debiera soslayarse el hecho capital de que EE. UU. es la sede de la mayor parte de las empresas transnacionales que operan en América Latina, con todas las consecuencias que de ello se deriva.

b) El no reconocimiento de las desigualdades de hecho, unido a una posición formalmente unilateral y gratuita por parte de EE. uv., son actitudes que perjudican más que benefician a América. Latina.

c) Sería útil, en consecuencia, suprimir términos tales como "ayuda", "generosidad", "solidaridad" y otros que sugieren que la contribución norteamericana no tiene contrapartida; si alguna vez se da una cuota de ayuda sin contrapartida, parece preferible que la generosidad o solidaridad que implica resulte del balance final de la relación más que de la declaración inicial de propósitos.

d) Por eso mismo no parece apropiado hablar de cooperación, término que supone úna cierta igualdad entre los interlocutores, y sí en cambio de intercambio y de negociación, exigiéndose que $\mathbf{c E}$. vv. explicite sus problemas e intereses, es decir, las contrapartidas efectivas que espera recibir por los aportes que promete realizar.

Es fundamental recordar que hemos entrado en esta década en medio de una crisis que afecta no sólo a EE. Uu. y América Latina sino al sistema internacional en su conjunto y que se prolongará seguramente durante unos cuantos años más. En esta crisis, a la que ningựa nación podrá escapar, EE. UU. está en su mismo epicentro, al extremo que su status como la nación más poderosa del planeta está seriamente amenazado. En consecuencia, su estrategia internacional estará determinada por esta situación, lo que implica graves riesgos para todos, y en particular, para los países que están en su esfera directa de influencia, como los de América Latina.

Al mismo tiempo, sin embargo, una crisis de tal profundidad puede crear posibilidades ciertas para un mejor entendimiento, en particular por el hecho mismo que los acontecimientos han demostrado que EE. UU. no tiene recetas apropiadas indiscutidas para este tipo de situaciones. Es el momento de hablar claro y de proceder con independencia. Exactamente como acaba de ocurrir en la votación de la oEA, rechazando el envío de una fuerza de paz a Nicaragua, posición que se acaba de reiterar con más fuerzas aún en la histórica reunión sobre la aplicación del TIAR a la crisis de las Malvinas.

Todos deben poner las cartas sobre la mesa y dejar de lado las mentiras tradicionales y la retórica falaz que las envuelve. 